Artículo de reflexión

Cómo citar: Baldoví, J. (2019).

¿En qué sentido puede hablarse de literatura como otra forma de conocimiento complejo? Elementos para un acercamiento entre ciencia y literatura. 15(28), 46-74. http:// doi.org/10.26620/uniminuto. polisemia.15.28.2019.46-74

ISSN: 1900-4648

eISSN: 2590-8189

Editorial: Corporación Universitaria Minuto de Dios - UNIMINUTO

Recibido: 05 julio 2019

Aceptado: 25 agosto 2019

Publicado: 25 octubre 2019
José María

Baldoví Giraldo

https://orcid.org/0000-0001-6 360-8126

Pontificia Universidad Javeriana Colombia

baldogi@hotmail.com

\section{¿En qué sentido puede hablarse de literatura como otra forma de conocimiento complejo? Elementos para un acercamiento entre ciencia y literatura}

\author{
In what sense can Literature be another \\ form of complex knowledge? Elements for \\ a dialogue between Science and Literature
}

\author{
Em que sentido se pode falar de literatura \\ como outra forma de conhecimento \\ complexo? Elementos para uma \\ aproximação entre ciência e literatura
}

\title{
Resumen
}

No solamente es necesario el diálogo entre las ciencias y las artes, especialmente la literatura. Es preciso, asimismo, concebir a la literatura como una forma de pensamiento complejo capaz de generar conocimiento. En ese sentido, una expresión como la novela constituye en sí misma un sistema complejo que bien puede compaginarse con las cualidades de las ciencias. La metáfora literaria es múltiple en sus connotaciones y hace universales las experiencias particulares; la expresión científica es unívoca y da razón del mundo exterior. Los intercambios entre ambos modos de entender el mundo pueden ampliar la visión compleja de la vida.

Palabras clave: complejidad, diálogo, humanidades, ciencias, literatura, novela, metáfora, sistema, vida.

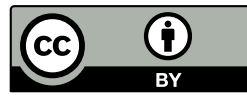




\begin{abstract}
Not only is a dialogue between the sciences and arts, especially literature, necessary. It's accurate, likewise, to conceive Literature as a form of complex thinking capable of generating knowledge. In this sense, an expression as a novel, constitutes in itself a complex system that can correlate with the qualities of the sciences. Literary metaphor is multiple in its connotations and makes particular experiences universal; scientific expression is precise and accounts for the exterior world. The interchange between both ways of understanding the world may expand the complex vision of life.
\end{abstract}

Keywords : complexity, dialogue, Humanities, Science, Literature, novel, metaphor, system, life.

\title{
Resumo
}

Não só é necessário o diálogo entre as ciências e as artes, especialmente a literatura. Além disso, é preciso conceber a literatura como uma forma de pensamento complexo capaz de gerar conhecimento. Nesse sentido, uma expressão como o romance constitui em si mesma um sistema complexo que bem pode se compaginar com as qualidades das ciências. A metáfora literária é múltipla nas suas conotações e torna universais as experiências particulares; a expressão científica é unívoca e dá razão do mundo exterior. As trocas entre os dois modos de entender o mundo podem ampliar a visão complexa da vida.

Palavras-chave: complexidade, diálogo, humanidades, ciências, literatura, romance, metáfora, sistema, vida. 


\section{Introducción}

El objetivo de este trabajo es abordar la palabra artística como una forma de pensamiento complejo capaz de alcanzar entendimiento, conocimiento, de ejercer discernimiento. Por tanto, la palabra literaria implica diálogo entre ciencia y literatura, entendidas ambas expresiones como obras abiertas según la perspectiva del pensamiento complejo, lo cual significa que entre ellas se producen fenómenos de intercambio de información, de reorganización, de adaptación y de formación estética. En ese sentido, el lenguaje constituye un factor determinante del problema, toda vez que es el lenguaje de la tribu, el lenguaje colectivo, el lenguaje además elevado a metáfora compartida, del cual se vale el arte literario para manifestar verdades tanto públicas como privadas, para recoger los términos de Aldous Huxley en Literatura y ciencia (1966).

Si ordenar el cosmos significa ordenar el discurso, la literatura fue la manera que el hombre encontró, después del relato mítico que unía a ser humano, la naturaleza y los dioses, para ordenar, según su entendimiento, la realidad, no solo exterior, sino también interna. Es decir, el abandono del mito: aglutinador, compacto, antidialéctico, cerrado, inalterable y circular, dio paso a una narración, ya no de acontecimientos sobrenaturales, sino más bien de acontecimientos humanos y por lo mismo históricos, en la medida en que la literatura cuenta aquello que le ocurre a la humanidad, sus aventuras, de una manera diversa, original y de sentido plural, pues la manera de contar y las palabras empleadas para hacerlo dejaron de ser las predilectas por la memoria mítica.

Así, la complejidad del mundo y de su observador se hizo manifiesta en la literatura, puesto que la no-linealidad, la indeterminación, la interacción, las dinámicas de las relaciones y la apertura, integraron la termodinámica del no-equilibrio que es la expresión de la escritura artística. Esta nueva dimensión acogió toda clase de combinaciones formales y de contenido que posibilitaron un verdadero diálogo entre el hombre y sus entornos.

Si las letras comprenden estas propiedades, es admisible pensar que son otra forma de interpretar, conocer y establecer una comunicación abarcadora entre el sujeto que conoce y el mundo por conocer. Lejos de jerarquizar, excluir o separar, la literatura, como las nuevas ciencias de la complejidad, recompone la unidad en la multiplicidad. La literatura, que no le disputa a la ciencia su poder de resolver, intervenir y modificar la vida y el mundo, sí nos trae de regreso a la ciudad Homo sapiens sapiens. Una ciudad compuesta de memoria e imaginación. Una arquitectura de la propia condición humana.

\section{La literatura como ciencia del ensueño}

La literatura, desde la Antigüedad, ha intentado no solo reunir en su seno la explicación filosófica y científica, sino que en ocasiones ha proclamado su propósito de encabezar la reflexión acerca de todo el conocimiento, siendo la 
literatura misma una forma de conocimiento, tal como intentaré exponerlo a lo largo de este artículo, pues el arte literario combina estética y discernimiento. No solo aspira a la belleza, que de por sí es ya el cumplimiento de una eterna aspiración humana: el ennoblecimiento espiritual de la existencia, la decoración del mundo material, el alivio sensual del costado más rudo de la vida. Es, también, un procedimiento para transmitir conocimientos profundos sobre los más diversos aspectos del hombre, del mundo y del cosmos.

El lenguaje de la creación novelística, entonces, no se ha negado a incorporar en su acervo materiales provenientes de las ciencias, claro que sometidos a una transformación que ha permitido que lo que se comunica pueda ser de comprensión universal. Pero una diferencia entre ciencia y literatura se ha mantenido: allí donde la ciencia ve cantidades, la literatura ve cualidades; allí donde la ciencia ve estructuras, la literatura ve individualidades; y allí donde la ciencia encuentra experiencias que ocurren en la realidad objetiva, las letras no excluyen las impresiones personales para interpretar el mundo exterior.

La relación recíproca entre la razón científica y la razón literaria o estética es en sí misma una relación compleja, que revela lo múltiple en la unidad del conocimiento. Busca la literatura, como lo hacen las ciencias, un desvelamiento del misterio. Sin embargo, la ciencia descubre o calla. Y si descubre o inventa, articula el engranaje de su lenguaje encriptado, sin ponderación aparente. Mientras que el lenguaje poético conserva el enigma y opta por la epistemología de la alegoría, del símbolo. ¿Es ello reprochable o menos digno de consideración que los resultados concretos de las ciencias? Aquí se sostiene que no. Aquí se alega que la literatura es otra categoría del conocimiento y que además religa todos los conocimientos. Porque así fue como la persona humana conoció en el principio y no ha dejado de conocerse a sí mismo ni de aprehender su entorno. ¿No acudió Freud a los mitos de Edipo y Electra para explicar los complejos identificados con esos nombres? ¿No creó Shakespeare tres emblemáticos tipos de lo humano a través de Próspero, el mago que renuncia a sus poderes sobrenaturales y acepta los límites del hombre; Ariel, espíritu aéreo, mágico, imaginativo; y Calibán, encarnación del salvaje?

La ciencia dice una cosa y nada más que una cosa. La palabra del artista es de múltiples significaciones. Esta última característica forma parte de la complejidad del pensamiento, siempre abierto a lo nuevo, al misterio, a lo diverso, a lo contradictorio. Esa dialéctica lo pone en movimiento. También lo pone en tensión con las ciencias.

Tal vez exista un punto intermedio para superar la disyuntiva de Gastón Bachelard, quien decía, como lo recupera Yáñez et tal (2009): "El mundo es bello antes de ser verdadero. El mundo es admirado antes de ser verificado" (p.42). ¿Necesariamente lo verdadero está ausente de belleza y la admiración desaparece cuando algo es verificado por nuestros sentidos? Sea cual sea la respuesta a este dilema, lo cierto del caso es que el interrogante implica una aproximación del arte a la incógnita del universo y al conocimiento. Antes de que las montañas, símbolo del romanticismo 
por excelencia, fueran vistas por la ciencia y se convirtieran en objeto de estudio disciplinar, Alexander von Humboldt escribió Cosmos, libro que funda la idea moderna de naturaleza y hace posible que el paisaje sea mucho más que un desafío lírico o una encarnación del subconsciente. Capacidad descriptiva, estilo fluido y precisión botánica y climatológica fueron los elementos literario-científicos literato-científicos con los cuales Humboldt creó una nueva teoría a partir de la cual admirar y explorar las cumbres, los volcanes y las cordilleras.

Así lo evoca William Ospina (2018) en El taller, el templo y el hogar:

Es muy probable que la idea del paisaje que hizo eclosión en la Europa de comienzos del siglo XIX en los poetas, en los artistas, en los músicos incluso, le deba mucho a lo que descubrió Humboldt viajando entre Ibagué y Buga. Porque fue allí donde Humboldt encontró algo que la ciencia de entonces no había encontrado: una teoría verosímil sobre de qué manera se disponen las especies vegetales sobre los territorios dependiendo fundamentalmente de la altura y del clima, observaciones que Humboldt obtuvo allí, que continuó en sus ejercicios de escalar los volcanes ecuatorianos, sobre todo, y que después confirmó en sus viajes por los Alpes. (p. 183)

De esta manera, conciencia crítica y conciencia estética ampliaron el panorama científico del romanticismo, una época cifrada por las experiencias individuales, la razón, los fantasmas, la imaginación y los sentimientos. La naturaleza simbolizaba las ondulaciones de nuestro pensamiento, era una de las premisas románticas. De modo que el mundo exterior se adecuaba a la mente. Sensación y razón eran las facultades a través de las cuales el hombre hacía su propia realidad. Eso cantaban los poetas y eso también verificaban los hombres de ciencia. Mundo exterior y percepción subjetiva establecían un sistema de intercambios y tensiones para penetrar en las entrańas de la naturaleza. Las corrientes universales circulaban a través de los sujetos .

Si convenimos en que lo expuesto hasta aquí señala un fiat lux de la creación literaria sobre las tinieblas humanas más recónditas, al igual que sobre el mismo quehacer de las ciencias, tal vez no sobre adentrarnos por un momento en las relaciones entre el sujeto y su contexto para entender mejor este vínculo o correspondencia, que también lo es de orden estético.

\section{Hombre y naturaleza: una relación compleja}

Si algo caracteriza a la ciencia es el afán de mantener un diálogo entre el hombre y la naturaleza. Sin embargo, esa conversación, en muchas ocasiones, ha sido más bien un monólogo en el que se ha intentado someter a la naturaleza a base de fragmentación y reduccionismo, pues durante mucho tiempo se pensó que el mundo no eras más que la suma de las partes y no un conjunto sistémico de diversos elementos en continua interacción. Pero a mediados del siglo XX, al agotarse ese modelo utilitarista, unívoco y unidimensional, la comunicación 
se fue tornando más abierta, de doble vía, razonable, multidisciplinaria y ética con el objeto de mejorar la interrelación del hombre consigo mismo y con el medio que lo rodea.

Evidencias tan preocupantes como el cambio climático, la destrucción de la capa de ozono y la amenaza de un armagedón nuclear, han conducido al abandono de la idea de acero de un universo autómata para transitar hacia una relación mucho más consecuente, reflexiva, parsimoniosa, sostenible y basada más en el desarrollo, entendido como una mejora en la calidad de vida y del entorno, que en el progreso eminentemente económico y material a cualquier precio. En el momento en que detecta que la naturaleza se le opone, que la materia se resiente de sus intervenciones, que el azar juega a los dados, el hombre revisa su determinismo para aceptar, por la tozudez misma de los hechos, que las relaciones con su entorno deben cambiar de manera radical para sobrevivir en el planeta. Es entonces cuando reconoce que esa relación ya no es unilateral, ni mecánica, ni reversible, sino sumamente compleja, por la red de vínculos entre la humanidad, la naturaleza, la ciencia y el pensamiento.

En consecuencia, el cambio de paradigma, del clásico (eterno y en pos de un orden fundamental), al complejo (temporal y caótico), es un hecho sin vuelta atrás. Con razón advertía Prigogine (1983):

Nuestra época se caracteriza, más que ninguna otra, por una diversificación creciente de conocimientos, técnicas y modalidades de pensamiento. Sin embargo, vivimos en un mundo único en el que cada ámbito de actividad implica a los demás; por ello considero esencial esclarecer ciertas concomitancias.

Un posible punto de partida para esta búsqueda es la convicción de que todo saber conlleva una construcción. Tanto en ciencias físicas, como, a fortiori, en las ciencias humanas, ya no es admisible la idea de realidad como algo dado. (p. 45)

De manera que la realidad era una edificación de orden intelectual que se había quedado anclada en vetustas coordenadas que dejaban por fuera características que se hicieron evidentes con la descomposición del átomo. La consideración de la termodinámica sacudió el pensamiento uniforme y quietista. Partículas, moléculas y novedades estelares conmovieron la visión de unidad, equilibrio y clausura. De manera que el reconocimiento de factores como la incertidumbre, el envejecimiento y renovación permanentes, la autoorganización y la aleatoriedad se convirtieron en parte de una realidad a la que era preciso aproximarse de una manera muy diferente al modelo clásico. Esa manera es la que ahora denominamos complejidad.

En aras de la claridad de los elementos en cuestión relativos a la complejidad, resulta pertinente detenernos un momento en el concepto de autoorganización, que se puede explicar así:

Si concebimos un universo que no sea más un determinismo estricto, sino un universo en el cual lo que se crea, se crea no solamente en el azar y el desorden, sino mediante procesos autoorganizadores, es decir, donde cada sistema crea 
sus propios determinantes y sus propias finalidades, podemos comprender, entonces, como mínimo, la utonomía, y podemos luego comenzar a comprender qué quiere decir ser sujeto (Morin, 1999, p. 96).

Por otro lado, para Prigogine (1993), los sistemas abiertos y vivos son el mejor ejemplo de la autooganización. Así lo explica en su obra ¿Tan solo una ilusión?, que me permito citar in extenso:

Para abordar el problema del orden biológico, tenemos que introducir un nuevo concepto: el de estructura "disipativa" [...] Es cierto que los biólogos insisten actualmente en el hecho de que el teorema de crecimiento de entropía se aplique al sistema completo, es decir, al sistema viviente, más su entorno. En otras palabras, un sistema vivo no puede compararse con un sistema aislado [...] sino más bien con un sistema abierto, es decir, un sistema que intercambie energía y materia con el mundo externo. [...]. Un sistema biológico, que metaboliza y se reproduce, debe, efectivamente, intercambiar energía y materia con el entorno; por lo tanto funciona como un sistema abierto. Por otra parte, como ya hemos puesto de relieve, el mantenimiento de la vida y el crecimiento dependen de un sinnúmero de reacciones químicas y de fenómenos de transporte, cuyo control implica la intervención de factores de alto grado no lineal [...]. Finalmente, el aporte de energía o de materia se efectúa generalmente en condiciones inestables, ya que los productos de reacción son expulsados del sistema vivo o enviados a otros lugares de la célula para que desempeñen otras funciones. En resumen: el funcionamiento de los sistemas biológicos parece cumplir las condiciones necesarias para que aparezcan las estructuras disipativas. (pp. 315-324)

La autoorganización es, por tanto, uno de los pilares fundamentales en cuanto al orden y al desorden del universo, al tiempo que es de la mayor importancia en la degradación, renovación y recomposición de la vida.

Resaltado este aspecto, podemos decir que la complejidad se perfila como la respuesta más adecuada en estos tiempos de crisis epistemológica y de tanteos metodológicos, pues la realidad parece haber desbordado los tradicionales cánones del conocimiento. También los nuestros son tiempos de apuro espiritual, de abuso utilitarista y de instrumentalización del ser humano. Incluso el lenguaje parece haber entrado en crisis, pues las nuevas formas y asociaciones que el mundo va revelando tienden a dejar muda la elocuencia de los sabios.

Por eso a la ciencia hay que acompañarla de reflexión, de orientación cultural y de sentido de trascendencia. También hay que dotarla de sentido común, de saberes locales y ancestrales, de moral asociativa, porque sin cooperación entre las disciplinas, entre ciencia y sociedad, y entre razón y vida, seguiremos ponderando la idea y la ecuación por encima de la realidad.

Razón tiene el papa Francisco (2015) cuando en su encíclica Laudato si dice que "una ciencia que pretenda ofrecer soluciones a los grandes asuntos, necesariamente debería sumar todo lo que ha generado el conocimiento en las demás áreas del saber, incluyendo la filosofía y la ética" (p. 89). 
De manera tal que parte del propósito de este trabajo es desarrollar una discusión acerca de la complejidad en su bifronte expresión de ciencias de la complejidad y pensamiento complejo. Así, las ciencias de la complejidad, a juicio de Maldonado (2009):

Estudian las transiciones orden/desorden. En otras palabras, se trata de estudiar y explicar de qué manera el orden se rompe, por así decirlo, y emerge el caos, o también, y en términos mucho más precisos, cómo es posible que a partir del desorden surja orden. [...] Es fundamental atender al hecho de que las ciencias de la complejidad atienden a los sistemas, fenómenos y comportamientos que tienen una complejidad creciente (p. 48).

A su turno, Morin (2008) ofrece su noción de complejidad a partir de la definición de Ashby:

¿Qué significa Complejidad, según Ashby? Es un modo de medir el grado de diversidad que se encuentra en un sistema. Esta idea es bastante interesante, porque dice que un sistema es una unidad, pero en esa unidad hay una diversidad. Es la unión de las dos nociones: de unidad y de diversidad. Y para mí, la Complejidad [...] es no principalmente la de indicar que complejo es la diversidad; sino es unir dos nociones que son antagonistas: unidad y multiplicidad o diversidad. (Morin, 2008, p. 29)

De una manera un poco más técnica y menos genérica, Gell-Mann (1998) afirma:

Una definición de complejidad surge de la ciencia informática, y tiene que ver con el tiempo requerido por un ordenador para resolver un problema determinado. Dado que este tiempo dependen también de la competencia del programador, el que se toma en consideración es el más corto posible, lo que se conoce habitualmente como "complejidad computacional" del problema. (p. 45)

Otro tratadista, como es Morales-Enciso (2012), recoge en su trabajo ¿Qué son las Ciencias de la Complejidad? por lo menos dos definiciones de un par de autores canónicos que resultan muy oportunas para el presente trabajo:

Yaneer Bar-Yam define Ciencias de la Complejidad como el estudio de sistemas con muchos componentes interdependientes. Y Melanie Mitchell propone que un sistema complejo es un sistema en el que grandes redes de componentes carecientes de cualquier tipo de control centralizado y que obedecen reglas de operación simples exhiben comportamiento colectivo complejo, procesamiento de información sofisticado, y adaptación mediante aprendizaje y evolución. (p. 2)

Ahora bien, es imprescindible tener en cuenta que sin la participación activa del sujeto que conoce y la mirada que arroja sobre el objeto de estudio no es posible entender el postulado del pensamiento complejo. Al respecto, cito la afirmación de Morin (2008): 
PROVIENE DE LA FUENTE Todo conocimiento es un modo de traducir y reconstruir a la realidad, no existe un conocimiento que tenga la cualidad de la fotografía, o de la película; todo viene de la traducción, de la construcción, viene de la mente humana; es decir, que la objetividad está ligada con la subjetividad, digamos, que al menos, está ligada con los poderes constructores de la mente, cualesquiera que estos sean, como por ejemplo, lo que estableció la demostración de Emmanuel Kant, el filósofo que demostró que nosotros podemos entender el mundo natural, el mundo de los fenómenos, con algunas categorías que vienen de la mente humana. (p. 39)

De esta forma, llegamos al punto crítico entre las ciencias de la complejidad y el pensamiento complejo, pues la diferencia más radical entre las ciencias y el pensamiento consiste en que la aproximación a la realidad no es simplemente una cuestión de método, también lo es de orden filosófico, ideológico y cultural. Dicho de otra manera, al insertar las ciencias en diversos contextos sociales, históricos y políticos, la complejidad, en toda su dimensión, es susceptible de ser objeto de variadas y hasta antagónicas consideraciones, percepciones e interpretaciones. Esto significa que los métodos impersonales, cuantificables, meramente instrumentales y universales de las disciplinas científicas reclaman, a ojos del pensamiento complejo, la incorporación explícita de la subjetividad para construir el edificio de la ciencia. En tal sentido me parece de claridad meridiana el pronunciamiento de quienes proponen una articulación entre las ciencias y el pensamiento de la complejidad, a partir de las luces de este último. Al respecto, me permito recoger el dicho de Rodríguez Zoya y Aguirre (2011):

El balance metodológico de la tensión pensamiento complejo-ciencias de la complejidad puede plantearse del siguiente modo. El pensamiento complejo intenta vertebrar un método no clásico para el estudio de la complejidad, este método atribuye de modo ineludible un rol central al sujeto de conocimiento en la elaboración de su estrategia cognitiva. Pero más aún, el sujeto del pensamiento complejo no es meramente un sujeto reducido a su dimensión epistémica-racional; por el contrario, es un sujeto abierto a la complejidad humana. Así entendida, la complejidad generalizada trasciende los límites del quehacer científico y concierne también "a nuestro conocimiento como ser humano, individuo, persona y ciudadano", dice Morin. (p. 156)

Como se puede advertir de lo arriba expuesto, existen diversas, y en principio complementarias, nociones de ciencias y pensamiento de la complejidad. De todas estas definiciones se puede sacar en claro que el mundo es uno y diverso y que absolutamente todo se encuentra intercomunicado, como una vasta red en la cual nada sobra y todas las piezas se prestan servicios unas a otras. Ahora bien, las ciencias de la complejidad, por su propio quehacer, tienden a excluir de su aparato metodológico y forma de conocimiento al sujeto que conoce. El problema neurálgico y de carácter formal, consiste en concebir la manera de incluir al hombre en el desarrollo del conocimiento científico, conocimiento que fundamentalmente se basa en el lenguaje matemático, mientras que las 
ciencias humanas basan su conocimiento especialmente en la reflexión y la subjetividad. Además, sería deseable que las ciencias fueran dirigidas por las humanidades. Y aquí me remito a la postura adoptada por Heidegger (1958) en su obra ¿Qué significa pensar?:

¿Está la tierra en nuestra cabeza o estamos nosotros en la tierra?

[...] No basta que admitamos, por así decirlo, solo en los momentos que escapan a la vigilancia científica, que nos hallamos naturalmente frente a un árbol en flor, para asegurar un instante después con la misma naturalidad que tal opinión representa por supuesto solamente una concepción ingenua de las cosas, por ser precientífica. [...] ¿Con qué título se toman las ciencias, a las que el origen de su propia esencia tiene que permanecer oculto, las atribuciones para emitir semejantes juicios? ¿De dónde les viene a las ciencias el derecho a determinar el lugar donde está situado el hombre, erigiéndose a sí misma en patrón y medida de tales definiciones? Esto, empero, ya tiene lugar con solo resignarnos en silencio a que nuestro estar frente al árbol sea únicamente una relación calificada de pre-científica con lo que seguimos todavía denominando "árbol". La verdad es que actualmente estamos más bien inclinados a repudiar el árbol en flor a favor de conocimientos físicos y fisiológicos que creemos ser superiores. (pp. 45-46)

Este desencantamiento del mundo y de la vida al que alude Heidegger, este hiperpragmatismo de la ciencia que contradice lo que percibimos y conocemos del mundo exterior, esta descomposición atómica y molecular de las cosas, es lo que parece ganar prestigio en disfavor de los sentidos, la poesía y la reflexión trascendental. Pero lo grave no es solo eso, sino que el hecho de despojar de sus afeites a la naturaleza y al hombre conduce al más desalentador de los nihilismos. ¿Acaso el encumbramiento apabullante y contemporáneo de las ciencias, que con tesón pareciera señalarnos que no somos más que un instrumento del entorno, un medio para la realización del designio ciego del universo, no es otra cosa que un síntoma de la decadencia del pensamiento?

$\mathrm{Al}$ respecto, no pocos pensadores han propuesto que una forma de evitar la decadencia del pensamiento consiste en incorporar a la vida ordinaria por lo menos algo belleza que ponga al hombre al abrigo de la total invasión de la ciencia y la tecnología. Por ejemplo, en La Via: para el futuro de la humanidad, Morin (2011) sostiene:

La relación estética no debe considerarse un lujo. Nos conecta con lo mejor y lo más sensible de nosotros mismos. Nos entrega un mensaje de autenticidad sobre nuestra relación con los demás, con la vida y el mundo. Nos proporciona la ocasión de maravillarnos, nos ofrece momentos de felicidad. Esta capacidad no puede sino ayudarnos a resistir la crueldad de este mundo y la barbarie humana. La reforma de vida comportaría una aspiración a los estados de trance que encontramos en todas las grandes emociones estéticas y lúdicas, en todos los entusiasmos, todas las exaltaciones, todos los ardores amorosos y festivos que nos acercan al éxtasis, son esos estados de trance, llenos de intensidad poética, los que dan la sensación de vida verdadera. En ellos nos perdemos para 
mejor reencontrarnos, en ellos nos reencontramos perdiéndonos. El éxtasis es el estado de trance que, entonces, se convierte en principal. Pero para evitar el riesgo de adicción a una sola fuente de placer o de éxtasis, es preciso mantener una pluralidad de aspiraciones, de deseos y emociones (pp. 254-255).

La literatura y las otras artes son, precisamente, las fuentes proporcionan esas emociones estéticas que llevan al individuo a estados de trance que lo conectan con planos de la realidad asociados con la espiritualidad, la introspección y la comunión. Aspectos estos que le ofrecen pasión a la racionalidad abstracta y sensibilidad a esa segunda naturaleza (la tecnociencia) creada por el hombre para morigerar su tránsito por la tierra. El debate metafórico, si así podemos también denominar a las obras del hemisferio poético de la humanidad, resulta saludable en la medida en que es propio de las artes obrar una especie de pausa y meditación alrededor de las "verdades" establecidas que dirigen o intentan dirigir la existencia.

Dicho de otra manera, el arte, en sus distintas manifestaciones, es una forma de ejercicio de la duda que observa con cautela aquello que el campo de la materia celebra como la antesala al estado de la felicidad. Felicidad cada vez más remota, pues lo que hasta ahora prevalece, a pesar de todos los esfuerzos de la biología, es el dolor.

El diálogo entre el ser, es decir, la literatura, las humanidades, y la realización de la idea, digamos las ciencias, es parte del pensamiento complejo, pues la unilateralidad del conocimiento puede conducir a la ceguera, uno de los grandes peligros del mundo contemporáneo. El contrapeso va por cuenta de obras como 1984 de George Orwell, o Un mundo feliz de Aldous Huxley. Saberes que también podrían sumarse a la discusión acerca de la complejidad, pues han permitido observar una serie de elementos de diverso orden, que, aunque ficcionales en su origen, han ido materializándose en los últimos tiempos. Es decir, la pesadilla en forma de literatura se ha convertido en una realidad social, política y científica.

Es así como en el caso de la distopía de Huxley — publicada en 1932- la tecnología, la hipnopedia, la propaganda y la eugenesia son mecanismos determinantes en el "Estado mundial" para la estabilidad y el amor a la servidumbre. La individualidad cede ante un sistema científico de castas, la formación intelectual es reemplazada por la repetición de eslóganes, el soma constituye un tranquilizante alucinógeno y de obligatorio consumo, y los humanos se crean a partir de tubos de ensayo para evitar errores y uniformar a la especie. Todos ellos son factores que garantizan el orden, impiden la rebelión, adormecen el pensamiento y producen seres entregados al trabajo, a la producción y al hedonismo. Estas condiciones, en la novela, se alcanzan mediante la eliminación de la familia, la diversidad cultural, la ciencia, la literatura, la religión y la filosofía. Si extrapolamos lo acontecido en Un mundo feliz a la actualidad de nuestros días, podemos comprobar que no estamos muy lejos de la inquietante predicción de Huxley: el cine, la televisión, la publicidad y la propaganda difunden un estereotipo humano que es cada vez más universal e incontestable. La economía y la política uniforman el modo de pensar y la conducta. Las artes y las letras 
se han tornado en expresiones de la industria del espectáculo. La ciencia no alivia los grandes dilemas de la humanidad. Y la tecnología - especie de soma - es la gran pedagoga de masas. Hoy los medios reemplazan a los maestros. La educación decae en favor de las adiciones cibernéticas. El individuo crítico, autónomo, distinto, en medio de este panorama, resulta una amenaza para la estabilidad mundial. Es un terrorista en potencia. Ya lo decía Huxley (1969): “Todo el mundo trabaja para todo el mundo. No podemos prescindir de nadie. Hasta los epsilones son útiles. No podríamos pasar sin los epsilones. Todo el mundo trabaja para todo el mundo" ( $\mathrm{p}$. 65). Es decir, por el beneficio de la totalidad se anula la diferencia. ¿Acaso nos estaremos dirigiendo a un sistema científico de castas, a la abolición del libre albedrío y a la servidumbre químicamentinducida como en la antiutopía de Huxley? La ciencia, que es la voz cantante de los tiempos, tiene la palabra. Y el poder, que a menudo prescinde de la palabra.

Por otra parte, ¿qué podremos argüir con respecto a la visión orwelliana, publicada en 1949? Que en ella la humanidad deja de pensar para dedicarse a sentir. Se destruye la palabra para crear la neolengua y el Partido difunde las tres consignas: "La guerra es la paz". "La libertad es la esclavitud". "La ignorancia es la fuerza". Para mantener esta situación de máxima sumisión, el Gran Hermano vigila e interviene en la vida, la conciencia y la intimidad de los súbditos de 1984. ¿No estamos acaso asistiendo a la emergencia de un lenguaje perfilado por la particular sintaxis de los soportes electrónicos? ¿No es verdad que la palabra, como manifestación particular, va en franco declive? ¿No es la búsqueda frenética de nuevas sensaciones uno de los rasgos más protuberantes de las nuevas generaciones? ¿No es cierto que como nunca antes el hombre se encuentra sometido a una suerte de reality show permanente? La vida privada e íntima no solo es pública; es parte de los mecanismos de control. Nadie puede escapar a la vigilancia de las cámaras. Todos dejan huellas electrónicas. Cada uno de nosotros ha sido codificado según sus gustos, necesidades, apetitos, predilecciones. Incluso nuestros vicios, que pensábamos estaban a cubierto, son explotados por la vasta red digital hasta la esquizofrenia. El arte de gobernar las mentes ajenas de Orwell es ya toda una matriz ideológica y mediática.

La ciencia, por tanto, no solo se ha visto incapaz de poner a la humanidad a salvo de sus peores delirios, los ha hecho posibles e irremediables. La modificación genética, por ejemplo, ya es posible y su intervención en la salud humana no solo permite pensar en la erradicación de tremendas enfermedades como algunos tipos de cánceres, sino que, al mismo tiempo, semejantes rectificaciones genómicas supondrían la aparición de nuevas enfermedades. Igualmente, el $\mathrm{ADN}$ de pueblos superiores mejorará en todo sentido con relación al ADN de los inferiores. Kipling dijo que ciertas características de las razas no eran producto de sus culturas, sino de su herencia biológica. Y ya conocemos el viejo e incorrecto dictum darwiniano. ¿Estará condenada la humanidad a clasificarse en humanidades según sus biologías para construir su historia? ¿De qué naturaleza humana estaremos hablando dentro de poco? Tal vez no sobre recordar que un investigador como Josef Mengele no era un nazi cualquiera. Era un hombre de ciencia que experimentó con seres humanos. No fue un caso aislado. Fue parte de la historia de la modificación genética. 
La ciencia, pues, ha contado con un correlato literario. $\mathrm{O}$, si se quiere, la literatura ha contado con un correlato científico. Como sea, vale anotar que los hombres de letras evitan las palabras técnicas, la jerga especializada, el hermetismo científico, para comunicar experiencias internas difíciles de compartir. Al hacerlo, esos hombres de letras organizan el lenguaje de manera tal que se haga apto para expresar la vida humana en sus planos íntimo y colectivo. No otra cosa hicieron en sus obras arriba mencionadas Huxley y Orwell. De manera que estos autores británicos buscaron ordenar, diríamos sistematizar, una serie de intuiciones no precisamente traídas de los cabellos, pues en la época de la publicación de sus obras se respiraba en el ambiente una evidente preocupación acerca de, por ejemplo, los estragos políticos, sociales y económicos que acarrearía un descontrolado crecimiento de la humanidad. Asunto este que Huxley soluciona en su novela, pero que aún hoy, en el mundo real, no parece tener una salida a la vista, pues los escasos recursos naturales están bajo la presión biológica del bípedo.

El hecho de que Huxley se hubiese ocupado de esta realidad - la superpoblación mundial- significa que como novelista y pensador se concentró en los temas de su tiempo. Temas que rebasaban su adhesión estética y literaria para encontrar en las inquietudes de la ciencia un contenido que fuera susceptible de llevar a la ficción para emitir su posición, no solo artística, sino también humanística, o sea, filosófica. Para Huxley, el vertiginoso desarrollo tecnológico no valía nada si no se avanzaba igualmente en caridad. Y la vida contemporánea parece haberle dado la razón, pues sin duda podemos observar un dramático desbalance entre el progreso tecnocientífico que apunta ahora a la posible colonización de otros planetas y el déficit de compasión para calmar las necesidades más elementales de por lo menos mil millones de seres humanos abandonados a su suerte. Son estos los seres inferiores, los esclavos, los infrahumanos, sobre los que Huxley advirtió en Un mundo feliz y otras novelas como Mono y esencia. Luego, resulta claro que el novelista entabló un debate epistemológico de tipo ficcional en el que cuestiones relativas a la indecibilidad, la incertidumbre, la emergencia y la autoorganización plantean un modo de entender la ciencia o de interrogarla, mediante la razón artística de la literatura, que por lo menos pone en tela de juicio el reduccionismo y el determinismo.

Orwell, a su turno, supo anticiparse a la sociedad del siglo XXI, completamente controlada por la red digital y de la cual nadie puede escapar. La omnipresente figura del Gran Hermano, que todo lo ve, todo lo escucha y todo lo dispone, ejerce una vigilancia de tal naturaleza que la vida y la conciencia de los súbditos quedan adormecidas, subyugadas y a expensas de la voluntad de un superestado. Es la vaporización del individuo. La verdad es relevada por la postverdad. Los tres eslóganes en la fachada del Ministerio de la Verdad recuerdan que La guerra es la paz. La libertad es la esclavitud. La ignorancia es la fuerza.

¿Era la novela de Orwell una mera ficción sin asidero en el mundo de su tiempo? Por supuesto que no. Las experiencias del estalinismo y del nazismo en lo relativo al control de la sociedad, a la manipulación de las masas, al 
ataque contra la individualidad y a la simplificación lingüística para no necesitar del pensamiento le permitieron al escritor columbrar un mundo vaciado de personalidad y relleno del doblepensar, aquel instrumento de dominación mediante el cual, en 1984, la mentira va por delante de la verdad hasta detener el curso de la historia. ¿Ha logrado la matriz electrónica introducirnos en ese doblepensar que lleva a la mente a aceptar por igual dos creencias contradictorias? Las fake news o noticias falsas, la omnipresencia de la imagen y el lenguaje deformado de los soportes digitales indicarían que la pesadilla orwelliana ha sido instalada en nuestras mentes. Efectos del desarrollo tecnológico.

Pero ¿cómo llega el creador literario a dar razón de esos mundos metafóricos de la realidad? Y ¿cómo puede el científico producir belleza sin traicionar su credo empirista? La ventaja del primero reside en la intuición, sin llegar a comprender necesariamente aquello de lo cual se ocupa en la ficción, mientras que el científico comprende racionalmente lo que hace, sin necesidad de depender de la intuición. Allí donde el uno intuye y el otro discierne metodológica y matemáticamente es donde tal vez se encuentra la simetría de dos mundos que se apartan por los principios y finalidades de cada uno, aunque se encuentran allí donde cada uno se fabrica un artefacto intelectual para aproximarse a la realidad.

De manera que, si el físico predice el desempeño de las partículas cuánticas apelando a la ecuación de Schrödinger, el escritor practica un saqueo de la realidad — según los términos de Vargas Llosa- para construir una de carácter ficcional, reflejo y negación de la misma realidad. En la formación de una imagen objetiva y en la formación de una adulteración de lo representado convergen la belleza y el entendimiento de aquello que ni para uno ni para el otro cambian dentro del flujo cambiante de las cosas.

Si, como alegaba Platón, el universo es un gran animal y todos participamos de su inteligencia, entonces el mundo y las obras de artistas y científicos responden al mismo modelo del cual unos y otros intuyen o conocen una parte de la forma total. Por consiguiente, si el animal que es el universo encierra en sí a todos los animales, la forma que lo comprende abarca todas las formas. Ergo, ciencia y literatura, desde esta perspectiva, comparten una armonía, un ritmo, una proporción. Un movimiento. Ese movimiento es lo que podemos calificar como obra de arte, que en el caso de la ciencia se traduce en leyes, magnitudes y relaciones de orden universal. En cuanto a la literatura, la empresa de reconstrucción o sustitución de la realidad adquiere un sentido igualmente universal en la medida en que las experiencias ficticias resultan admisibles e incluso acogidas por todos los hombres.

Aquella pluralidad en la unidad - el desdoblamiento múltiple de la forma de todas las formas y la convergencia universal de las imágenes científica y literaria - nos remite a la comunicación y a la comunión, tan sustanciales en el despliegue del pensamiento complejo. En esa encrucijada de caminos para el conocimiento, la prosa de la ciencia y la poesía del arte comparten visiones, estéticas, lenguajes y búsquedas. El lenguaje unívoco y práctico de la ciencia y el lenguaje connotativo de la literatura confluyen en 
la elaboración de una representación útil y no menos bella de una realidad poliédrica y en permanente transformación. Objetividad y subjetividad se funden para ensayar, como en el caso del bosque consumido del techo y la piedra quemada de Notre Dame, una máquina arquitectónica - o un artefacto simbólico o un aparato matemático - para reproducir en la tierra las leyes del cielo y transportar las almas a las alturas.

Si ciencia y literatura pueden llegar a coincidir en elocuencia, belleza, multiplicidad y apertura, parece necesario plantear una cooperación entre ambas órbitas con el objeto de alcanzar una consonancia que permita resignificar la creación científica como medio de adquisición de conocimiento no exento de ética y formas artísticas, mientras que la creación literaria, más que una contemplación, bien podría admitirse que es otro modo de acción de doble consecuencia: por una parte, de demolición de lo anacrónico y valetudinario; y por otra, de revelación o intuición de realidades escondidas.

\section{La naturaleza es humana, demasiado humana}

Ahora bien, es cierto que no podemos vivir divorciados del mundo, pero no es menos cierto que el mundo, para que sea, para que exista, depende de la conciencia del hombre. La misión del pensamiento complejo consistiría en crear la armonía entre el mundo, los medios para conocerlo y la conciencia para admirar ese mundo y administrarlo sin dañar su belleza, sin agredir su existencia, sin menoscabar su equilibrio. Esto supone que todo modelo científico de abstracción de lo real se deje interrogar o interpelar por la razón filosófica, ética y estética.

Para protegernos de una desviación del conocimiento que nos pudiera conducir al precipicio y acercarnos a una visión un poco más artística y respetuosa de la naturaleza, me remito a De Sousa Santos (2009) para citarlo ampliamente:

La ciencia del paradigma emergente es más contemplativa que activa. La cualidad del conocimiento se mide menos por lo que él controla o hace funcionar en el mundo exterior que por la satisfacción personal que da a quien a él accede y de él participa.

La dimensión estética de la ciencia ha sido reconocida por científicos y filósofos de la ciencia de Poincaré a Kuhn, de Polanyi a Popper. Roger Jones considera que el sistema de Newton es tanto una obra de arte como una obra de ciencia. La creación científica en el paradigma emergente se asume como próxima a la creación literaria o artística, porque a semejanza de éstas pretende que la dimensión activa de la transformación de lo real (el escultor al trabajar sobre piedra) sea subordinada a la contemplación del resultado (la obra de arte). A su vez, el discurso científico se aproxima cada vez más al discurso de la crítica literaria. De algún modo, la crítica literaria anuncia la subversión de la relación sujeto/objeto que el paradigma emergente pretende operar. En la crítica literaria, el objeto de estudio, como se diría en términos científicos, siempre 
fue, de facto, un súper-sujeto (un poeta, un romántico, un dramaturgo) frente al cual el crítico no pasa de ser un sujeto o actor secundario. Es cierto que, en tiempos recientes, el crítico ha intentado sobresalir en la confrontación con el escritor estudiado al punto de poderse hablar de una batalla por la supremacía, trabada entre ambos. Pero porque se trata de una batalla, la relación es entre dos sujetos y no entre un sujeto y un objeto. Cada uno es la traducción del otro, ambos creadores de textos escritos en lenguas distintas, ambas conocidas y necesarias para aprender a gustar de las palabras y del mundo.

Así resubjetivizado, el conocimiento científico enseña a vivir y se traduce en un saber práctico. (pp. 53-54)

Discusiones como las planteadas se presentan como indispensables, pues la ciencia debería proponerse, entre otras cosas, integrar a su quehacer los intereses de diversos sectores de la humanidad (como las comunidades campesinas y los pueblos amerindios y afrodescendientes) que se han visto vulnerados por una forma de conocimiento que, en muchas ocasiones, solo beneficia a la parte más poderosa del mundo. Por otro lado, la presión demográfica, los no siempre muy favorables efectos de la tecnología, la posibilidad de integrar saberes alternativos o ancestrales y la certeza de la limitación de los recursos naturales, han despertado una conciencia planetaria que reclama una pausa y una meditación acerca de los alcances de nuestra comunicación con el universo.

Por lo pronto, el mundo de la ciencia parece estar de acuerdo en que el entorno no es un medio para alcanzar la plena satisfacción del hombre, sino un fin en sí mismo, un ser, un sujeto, y que, por consiguiente, debe ser tratado con responsabilidad. Aquí podemos percibir que las ciencias de la complejidad y el pensamiento complejo se pueden encontrar para prestarse mutuos beneficios, con el objeto de preservar a la naturaleza, de ofrecerle al hombre una segunda oportunidad sobre la tierra para que abandone el paradigma clásico del conocimiento y se relacione con el mundo de una forma mucho más respetuosa, creativa e inteligente. No hay razón para que las dos columnas de la complejidad (ciencias de vanguardia y pensamiento complejo) se repudien mutuamente. Entre ellas es posible la cooperación, no solo la contradicción; el reconocimiento de las dos es imprescindible para abordar la realidad en toda su dimensión o en sus incontables dimensiones; ambas son claridades, no anulaciones. Las dos son viáticos para el nuevo pensar y el nuevo quehacer. Que las dos columnas se requieren, es un hecho que Rodríguez Zoya y Aguirre (2011) explican así:

La propuesta del pensamiento complejo propone la reconfiguración epistemológica tendiente hacia un conocimiento transdisciplinar, en el cual, necesariamente, la ciencia tiene que ser articulada con otras formas de conocimiento. Esto no implica renunciar ni abjurar de la ciencia y del conocimiento científico sino, por el contrario, la necesidad de problematizarlo, criticarlo e incluirlo en un marco de comprensión más rico. En esta línea, el pensamiento complejo desarrolla también una propuesta ética y política que aborda la crítica al modo civilizatorio hegemónico en Occidente, como objeto central de su problemática. 
Considero política y humanamente riesgoso, y epistemológicamente inaceptable, creer que solo con buenas herramientas tendremos lo suficiente para crear una mejor ciencia. Entiendo por mejor ciencia aquella capaz de abordar los problemas humanos fundamentales y, también, aquélla capaz de ser juzgada en base a criterios ético-políticos vinculados a las necesidades sociales de los pueblos. (pp. 163-164)

Por idéntico camino se despliega el pensamiento de Morin (1981), para quien: "Desde hace más de medio siglo sabemos que ni la observación microfísica ni la observación cosmo-física, pueden separarse de su observador. Los más grandes progresos de las ciencias contemporáneas se han efectuado reintegrando al observador en la observación (p. 23).

También Prigogine y Stengers (2004), en su texto La nueva alianza: metamorfosis de la ciencia se proponen cerrar la grieta entre las ciencias y las humanidades:

¿Qué lección podemos sacar de esta rápida exploración de unos cuantos temas filosóficos? Si, yendo por caminos diferentes, ciencia y filosofía han de poder encontrarse y poner así fin a una oposición que quiebra nuestra cultura; si la ciencia debe poder ser un método del que participe la cultura y no una operación inaccesible, lejana y fascinante, debe terminar el reino de la abstracción que acaba por paralizar el objeto frente al sujeto. La naturaleza, objeto de la ciencia, es la que produce los hombres de ciencia; esta exigencia de comprensión coherente no debe ciertamente encontrar en las teorías científicas una respuesta única y suficiente, sino que debe tomar significado en el seno de la ciencia, poder ser entendida por los hombres de ciencia como tales. (p. 135)

La ciencia y las humanidades se siguen esforzando por comprender mejor a la naturaleza, pero en los últimos tiempos han llegado a la conclusión de que pueden afinar, corregir y amplificar sus respuestas si dejan a un lado la omnisciencia y más bien se auxilian e interrelacionan para generar nuevas vías de diálogo con el mundo.

A propósito de la tan mentada simetría e integración de las ciencias y del pensamiento, considero que "la ciencia", como recapitula Sábato (1981) al reproducir las palabras de A. N. Whitehead:

Debe aprender de la poesía; cuando un poeta canta las bellezas del cielo y de la tierra no manifiesta las fantasías de su ingenua concepción del mundo, sino los hechos concretos de la experiencia "desnaturalizados por el análisis científico" (p. 25).

Y que la ciencia va aprendiendo de la poesía y del arte en general es tal vez un hecho que se cristaliza a medida que el saber retorna al seno de la sociedad. Es así como Prigogine y Stengers (2004) retoman las palabras de un célebre físico austríaco para defender su postura en favor de la integración de la ciencia a la cultura, en el sentido más amplio de este concepto: 
Erwin Schrödinger escribió una vez, para gran indignación de muchos filósofos de la ciencia, que: “... Hay una tendencia a olvidar que toda ciencia está en estrecha relación con la cultura humana en general, y que los descubrimientos científicos, incluso aquéllos que en el momento parecen los más avanzados, esotéricos y difíciles de comprender, no tienen sentido fuera de su concepto cultural. Una ciencia teórica no consciente de que aquéllas de sus construcciones consideradas relevantes y trascendentes están eventualmente destinadas a ser enmarcadas en conceptos y palabras, que tienen sentido para una comunidad educada, y de convertirse en parte y parcela de una imagen general del mundo; una ciencia teórica, vuelvo a insistir, que olvida esto, y en donde los iniciados continúan cavilando en términos solo entendidos por algunos compañeros de viaje, estará necesariamente aislada del resto de la humanidad cultural; está avocada a la atrofia y a la osificación". (p. 42)

Entonces, al considerar la ciencia como parte de un todo mucho mayor, como lo es la cultura, los descubrimientos, los avances, las nuevas explicaciones, los últimos artilugios y las inusitadas exploraciones permitirán no la separación de la realidad y su abstracción científica, sino la incorporación al mundo del hombre de unos pliegues de la naturaleza y del universo que hasta hace muy poco se habían mantenido ocultos. Hoy, como ayer, científicos, filósofos y creadores de arte se han planteado los mismos asuntos: el tiempo, el destino, la muerte, la transformación, la irreversibilidad, la incertidumbre... y cada uno ha intentado resolverlo, explicárselo o interrogarlo. Hoy sabemos que no tenemos que escoger entre el determinismo y libertad, como tampoco entre naturaleza y pensamiento; mucho menos, entre hombre y mundo. La perspectiva, ahora, es la comunicación con la naturaleza, y en esa medida, la naturaleza es un lienzo, un texto, una imagen, en suma, una obra de arte.

Por esta razón alego que las luces que brindan el arte, el humanismo y la cultura son las más recomendables para que orienten, interpreten y modulen la colosal locomotora de la ciencia, que como argüía Heidegger (1958) en su obra ¿Qué significa pensar?, "no piensa" (p. 13). Por ello, se impone una nueva alianza entre la humanidad, la ciencia y la cultura; pero una alianza que le devuelva al universo el encanto que el lenguaje matemático de la ciencia le arrebató en provecho del examen pitagórico.

\section{La ciencia no es el único pan de la vida, también lo son el arte y la poesía}

A pesar de ese anhelado concordato entre ciencias y pensamiento, que todavía se encuentra en desarrollo, debo indicar, asimismo, que al menos dos vértebras fundamentales del presente texto son de la sustancia proveniente de "todas las plumas que empuñaron los poetas", como dijo Mallarmé al pie de la tumba de Edgar Allan Poe. Dos de esas plumas corresponden a Nietzsche, otra, a Emily Dickinson, y hay una más, la ya la mencionada de Heidegger, que corresponde al pensamiento. De modo que literatura y filosofía, es decir, las humanidades, 
acuden para fortalecer mi planteamiento de que sin la concurrencia del arte y del logos, las ciencias, en virtud de su obrar, a menudo con anteojeras, pueden arrollar el pensamiento; y lo que demandan nuestros tiempos, todos los tiempos lo han demandado, es pensar de más para iluminar y conducir la trepidante acción de las ciencias, que, como les corresponde, obran de más.

Por lo anterior, debo enfatizar que otro tema que sobresale en este trabajo es el de la preocupación por la palabra de la tribu, porque la palabra es la casa del hombre: el signo complejo y complejizante que interpela, interpreta, fecunda e inventa. Y, sobre todo, religa. Y si la palabra religa y comprende al hombre y todo lo que este crea, entonces la palabra de las humanidades y de la literatura es fundamental para el entendimiento más completo al que se pueda aspirar, porque es en ella donde el hombre se encuentra consigo mismo . La palabra es el espejo enterrado, el reflejo perdido que siempre buscamos para saber qué somos, quiénes somos y cómo somos. Este es el código introspectivo, el profundo, el que piensa.

El otro código es el de las ciencias, el externo, el de la potencia, que, por complejo que sea, no transmite la polifacética experiencia humana: en él las impresiones están desterradas o difícilmente asimiladas, porque el lenguaje flemático, unívoco y abstruso de las ciencias es un medio para verter las experiencias terrenales, no las del alma. En cambio, la palabra de la filosofía, de las artes, de la literatura abre las puertas de la percepción a otros mundos que están más allá o más acá de la vibración de las partículas subatómicas.

Por cuenta de la palabra el hombre sí es de este mundo y el mundo no es un tránsito platónico al más allá, ni una república matemática del homo faber y sin atributos. De la palabra del artesano hasta la palabra del filósofo depende la ciencia de lo tangible y escondido, de todo lo público y lo privado. La palabra, la que se lleva el viento y la escrita, fue el primer asomo que tuvo nuestra especie del abismo plural. Aquello que llaman complejidad.

Mi partido, entonces, es el del humanismo. Eso no me impide estar a la espera del Dante de la microfísica o del Milton de la termodinámica. Quiero oír lo que hay bajo la vestimenta de barro y muerte que encierra a las almas, pero que yo sepa, ningún artefacto ha podido capturar el sonido de la armonía de los cuerpos yacentes o el silencio intergaláctico. Hasta ahora, ese ha sido el campo magnético del poeta o del pensador. La ciencia puede descomponer y rehacer el pan, incluso, puede suplantar la harina y demás ingredientes, puede también cocerlo. Lo que no puede es amasarlo como lo amasa la poesía de las manos. La palabra es la ciencia y es la estancia del hombre. Y creo que la estancia de la palabra debe presidir el banquete del conocimiento. Y presidir no significa desplazar o someter a la ciencia, más bien quiere decir que a la ciencia, por ser frígida, no le vendría mal untarse de la arcilla de las emociones, de las impresiones, de las palpitaciones del arte y de los valores de la cultura. Tal como lo sugieren Prigogine y Morin

Creo firmemente que ciencia y humanismo son los pilares de una sola cultura que han permitido al hombre hacerse cargo de su vida y su destino 
a partir de la crítica de la civilización y de la creación del espíritu. Como resulta apenas lógico, sin una adecuada comprensión de nosotros mismos y de lo que nos rodea, nos resulta poco menos que imposible conocer y comprender a los demás y entender el mundo que nos cobija. No solo hemos llegado a un estado de cosas en el cual se reclama por el cuidado del medioambiente, también se clama por la protección de nuestro otro prójimo: los animales, que comparten con nosotros un sistema nervioso que nos hermana en el dolor de la existencia, y a los que incluso se les vienen reconociendo derechos. Son, pues, ciencia y humanismo, un entramado de tal magnitud que nos permite decir con Tagore (1976) "porque tú moras en mí y yo en ti" (p. 208), puesto que somos parte del todo y todos juntos somos más que el todo, porque no somos un mero recipiente, sino una fusión trascendental. Se trata de un clamor, y de nuevo recurro a Tagore (1976), “por el más allá que está solo en nosotros" (p. 208).

Pero hay también en esa compenetración de ciencia y humanismo una cualidad subversiva que se remonta a Solón y que podríamos asumir en esta esquina de la Tierra, pues el reformador ateniense predicaba que los plebeyos, vistos como de origen animal, debían reflexionar sobre sí mismos para reconocerse de la misma naturaleza humana que los nobles, que se consideraban de origen divino. En tal sentido, la arriba mencionada crítica cobra el valor de lo que Gramsci (2014) sostiene en Crónicas de Turín:

Crítica quiere decir justamente esa conciencia del yo que Novalis consideraba como finalidad de la cultura. Yo que se opone a los otros, que se diferencia y, habiéndose creado una meta, juzga los hechos y los acontecimientos, además de en sí y por sí mismos, como valores de propulsión y repulsión. Conocerse a sí mismos quiere decir ser sí mismos, quiere decir ser dueños de sí mismos, diferenciarse, salir fuera del caos, ser un elemento de orden, pero del propio orden y de la propia disciplina, por causa de un ideal. Y éste no se puede alcanzar si no se conoce también a los demás, su historia, los sucesivos esfuerzos que han realizado para ser lo que son, para crear la civilización que han creado y a la que nosotros queremos sustituir por la nuestra. Quiere decir tener nociones sobre la naturaleza y sus leyes que gobiernan el espíritu y aprenderlo todo sin perder de vista el objetivo último, que es conocerse mejor a sí mismos a través de los demás y a los demás a través de sí mismos (p. 68).

De lo anterior podemos colegir, por lo pronto, que la complejidad, lo formado por distintos elementos interrelacionados con el objeto de establecer una realidad, no es una consecuencia a la cual se llegue por generación espontánea o por la fatalidad de las cosas. Se llega a ella por la fuerza de la voluntad, por la apropiación individual y colectiva de la personalidad, porque se descubre la función que se desempeña en la vida. Ese es el valor de la cultura, que es además un valor histórico, no una condición natural. Y para alcanzar esa cultura se necesita conciencia, la conciencia que otorgan las ciencias, el arte y el humanismo. De manera que la conciencia se construye, se examina, se transforma, se libera. Es la plusvalía de la cultura. Lo importante es que ese rendimiento no le sea enajenado al hombre en provecho de intereses contrapuestos a sí mismo y al mundo. Esa suerte de resistencia: la de conservar del lado del hombre el 
conocimiento y la libertad de conciencia que ello supone, es de resorte del humanismo, y de las artes especialmente. Se trata, entonces, de impedir que seamos desalojados de la cultura.

Sé muy bien que este rodeo que acabo de hacer puede importunar a no pocos lectores; pero, según entiendo las cosas, la propuesta de la complejidad es el producto del desconcierto ante la magnitud de la ignorancia que avanza como una aplanadora. Ese desconcierto, que hoy observamos como nunca antes, es el que por todos los medios tratamos de ordenar, comprender y relacionar. Ese desconcierto también amerita, cómo no, un discernimiento ético, estético y humanístico.

Dicho lo anterior, tal vez valga la pena añadir que la reproducción de los objetos y los fenómenos por parte de la ciencia, y su recreación e interpretación por parte de las artes y el pensamiento se cruzan en la metáfora, esa figura literaria que alude a la identidad de un objeto de un modo distinto, pero no tanto como para que las entidades comparadas no contengan un núcleo común. Metáfora es el universo, uno y múltiple, como la complejidad.

Si admitimos que la literatura forma parte de la ecología del conocimiento, tal vez no esté demás abundar en el concepto de pensamiento de la complejidad como entramado cooperativo de saberes, en el cual el ser humano y sus extensiones tecnológicas, científicas, culturales y estéticas se reconectan con el objeto de recuperar la esencia del fenómeno humano.

\section{Religar: religión del conocimiento}

En resumidas cuentas, complejidad significa que todo está conectado $\mathrm{y}$ es interdependiente, que nada sobra y todo es insuficiente, y que, por consiguiente, el hombre, antes señor de la naturaleza, hoy no puede pretender ser más que un componente, en todo caso definitivo, del laberinto del universo, razón por la cual debería guiarse por lo que Max Weber llamaba ética de la responsabilidad. Por supuesto que esta visión se encuentra en consonancia con las aproximaciones de corte humanista y de las ciencias sociales, pues las ciencias de la complejidad suelen poner el acento en la dinámica misma del átomo, de la molécula, del logaritmo, del flujo de información, del azar...

Pero si queremos un concepto mucho más científico e imparcial, me parece que ver el mundo como un conjunto de sistemas complejos adaptativos, al modo de Gell-Mann (1998), tampoco está mal, porque en realidad esa es la gran conclusión que arroja el modelo de la complejidad: una organización cuyos resortes y componentes internos intercambian información, energía y materia con el objeto de adecuarse a distintos contextos. Además, los sistemas complejos adaptativos no son cerrados y, por lo tanto, son incompletos, pues su tendencia natural apunta hacia la renovación y la metamorfosis, hacia la constante desaparición y refundación. 
También podríamos decir que confusión e incertidumbre, como argumenta Morin (2008), constituyen "los signos precursores de la complejidad", y así volvemos a como estábamos al principio, pero al principio de los tiempos de la Grecia clásica, porque lo que buscaban sus filósofos - y por filósofos también se entendía científicos- era poner orden en la casa y en el cosmos, que era todo caos. Naturalmente, Morin quiere dar a entender que la complejidad es un medio de liberación de la confusión y la incertidumbre a partir del cual se funda una organización, pero con esa constatación de Perogrullo no parece que lleguemos muy lejos.

Si fuésemos serios, deberíamos admitir que todo lo que tenemos son aproximaciones y metáforas y una dosis, más bien elevada, de fe, de creencia en nuestros ladrillos imaginarios, que de cuando en cuando se corresponden con los ladrillos del universo. Desde que el hombre es hombre, los objetos de devoción se han ido relevando. Desde los dioses de la Naturaleza y del Olimpo hasta el vacío esencial que parece sugerirnos no solo el budismo, sino también la física contemporánea. Si todo es maya, 'ilusión', ¿para qué tanto alboroto? Calderón lo dijo mejor: "La vida es sueño, y los sueños, sueños son".

En fin. Si de lo que se trata es de resanar nuestra relación con la naturaleza, primero tenemos que restablecer las relaciones entre nosotros. Es decir, religar, 'volver a unir lo roto', del latín religare, 'atar fuertemente', que es lo que significa religión: 'reunir, recoger, vincular'. ¿Religión de la complejidad? Es posible. La catástrofe ecológica nos muestra el precipicio que separa al hombre de su entorno. Por eso hay que suturar heridas y tenderle una mano cálida a la naturaleza. Tal como lo subraya Rabindranath Tagore (1976) en su obra El sentido de la vida, al comparar la forma en que Oriente y Occidente se acercan a la Naturaleza, cito in extenso:

Desde dos puntos de vista podemos ver un camino: como espacio que nos separa del objeto deseado, y entonces cada paso es una conquista, o como algo que nos conduce a nuestro destino y en ese caso está dentro de nuestros fines. De esta segunda forma es como la India considera a la Naturaleza. Al recorrer el camino solo aspiramos a ganar aquello que espontáneamente nos sea ofrecido.

Para el hombre hindú, lo esencial es hallarse en plena armonía con la Naturaleza. El pensamiento es posible porque el espíritu está en buenas relaciones con las cosas que le rodean. Si las fuerzas naturales nos ayudan, es porque el poder del hombre está en armonía con los poderes universales. Y, en todo caso, la finalidad de esta ansia no puede nunca contradecir a la que se manifiesta en la Naturaleza.

En Occidente, esta finalidad pertenece a los animales y a los seres inanimados, como si existiese una extraña solución de continuidad en el principio de toda naturaleza. Para el hombre occidental, todo lo que es inferior es naturaleza y lo que lleva el sello de la perfección es lo humano. [...] El hombre hindú, en cambio, se siente feliz al reconocer su parentesco con la Naturaleza y sus relaciones de continuidad con todo lo que de ella nace. En la India, el concepto de unidad en la creación no fue solo suceso filosófico o teológico, sino que el objeto en sí de la vida consistía, ante todo, en realizar la equilibrada armonía entre la 
acción y el pensamiento. La meditación y la entrega generosa ha permitido, sin embargo, que todo tenga una valoración espiritual. (pp. 21-22)

Tal vez, parte de la angustia existencial del hombre contemporáneo radique en que se perciba simplemente como individuo apartado, huérfano, y no como parte de un sistema que lo acoge y supera: el universo. Por esta misma línea de reincorporar al hombre en el mundo, se mueve el pensamiento de Morin (1999):

Desde hace más de medio siglo sabemos que ni la observación microfísica, ni la observación como-física, pueden separarse de su observador. Los más grandes progresos de las ciencias contemporáneas se han efectuado reintegrando al observador en la observación. Cosa que es lógicamente necesaria: todo concepto remite no solo al objeto concebido, sino al sujeto conceptuador. Encontramos de nuevo la evidencia que despejara, hace dos siglos, el filósofo-obispo: no existen los "cuerpos no pensados". Ahora bien, el observador que observa, el espíritu que piensa y concibe, son indisociables de una cultura, y por tanto, de una sociedad bic et nunc. (p. 23)

Confieso que me agrada que la complejidad, como si persiguiera que la unión de las cosas con el hombre que se predica en Oriente tumbe de su pedestal ; es justo y necesario, por su prepotencia y el peligro que entraña aun para sí mismo. Está bien que ahora la vida vaya estando menos al servicio de la inteligencia y de la ciencia, y que más bien la inteligencia y la ciencia empiecen a ser utensilios para la vida. Comparto la visión que no solo las ciencias, sino también el pensamiento de la complejidad, vienen predicando, a saber, que en buena medida la historia de la humanidad es la historia del fracaso de la inteligencia. Como es apenas natural, el estropicio hay que remendarlo y proyectar un futuro menos aciago de lo que fue el pasado. Pero a veces me da por pensar que lo que se proponen las ciencias de la complejidad es tomar las riendas de la cultura y erigirse en poco menos que en religión. Estamos en una época de beatería y de osadía al mismo tiempo.

De beatería, según veo, porque todavía asistimos al estreno de un conjunto de ciencias que están revolucionando el panorama de la vida y del universo en su totalidad. Por ello, mal que bien, se le rinde pleitesía a la novedad porque desafía, desacata, desobedece, critica, depone y desacredita a la ciencia vieja, caduca, pero que todavía colea. Y de osadía, porque sin duda el futuro, que tiene una fuerte fragancia a presente, es de propiedad privativa de las ciencias (o eso parece), entonces se le lleva en andas, se le acompaña de cuadrillas bien reforzadas, se impone por el peso mismo de sus seguras inseguridades, para no perder de vista el credo de lo complejo, y se expresa en unos complejísimos lenguajes, intrincadas ecuaciones, escurridizas descripciones e inasibles composiciones contra lógicas, ametódicas y aleatorias.

Destaco de la complejidad, de las ciencias y del pensamiento, su invocación a la cooperación; solo así han sobrevivido las civilizaciones, de esa manera se ha prestado auxilio la naturaleza, no de otra forma sobrevive el hombre. Pero me pregunto si la virtual o real constatación de la entropía 
de la especie humana y de la emergencia del individuo, como si fuera un organismo vivo más puesto en la naturaleza, que evidentemente lo es, sea la respuesta al desencanto del mundo.

En fin, considero que el ser humano se disuelve en las propiedades o fenómenos de lo visible e invisible, del materialismo y de la filosofía. Observa, cualifica, cuantifica, es, además, parte del objeto, de la naturaleza, de la piel del cosmos. Es pensamiento y espejo. Es otra cosa, no solo hombre. Es un material más de la organización del infinito, por abierto y no cerrado, aunque finito por el tiempo y el desgaste molecular y térmico.

En consecuencia, estamos de acuerdo en que la ciencia está en pos de un nuevo paradigma: el de la complejidad, y para entenderlo debe empezar por quien lo formula, es decir, el hombre y su relación profunda, por cuanto los actos o ritos humanos responden, según Morin (2008), a "un paradigma complejo, [que] es un paradigma que pudiera entender la relación compleja entre la parte biológica del humano y la parte mental-biológica del humano" (p. 31). Aquí Morin no rompe con la tradición humanista, pues al incluir lo mental en su exposición todavía le deja alguna esperanza a la rama de los primates a la cual pertenecemos, esperanza que el francés liga a la conciencia. El humano no es para él otro animal, tan solo una especie más, es un ser capaz de una "ética de la comprensión" (Morin, 2008, p. 40).

A pesar de que el pensamiento de la complejidad se hace eco de lo anteriormente expuesto y demanda una apertura que trascienda los campos propios de las ciencias para ponernos en contacto con la esencia del ser humano, Morin (1981) y De Sousa Santos (2009), integrantes de esta corriente, entienden la labor del pensamiento de la complejidad de maneras diversas. En primer lugar, aunque ambos forman parte del bloque del pensamiento complejo, es decir, aquel que se propone recuperar al sujeto como centralidad cognoscente y que se identifica con una propuesta de filosofía de la conciencia, se apartan de manera decisiva a la hora de concebir sus modelos de conocimiento.

Según De Sousa Santos (2009), resulta imprescindible que los grupos sociales del hemisferio Sur se apropien del conocimiento total o universal para ponerlo a disposición de "proyectos de vida locales, sean ellos reconstruir la historia de un lugar, mantener un espacio verde, inventar un nuevo instrumento musical, erradicar una enfermedad, etc." (p. 49). Si entiendo bien, y conociendo de antemano la postura política del sociólogo portugués, pues esta postura apunta, evidentemente, a la necesidad de plantear una recreación, adecuación o metamorfosis del conocimiento en función de una clara soberanía social, política, económica y científica por parte de aquellos que Frantz Fanon (1961) llamó Los condenados de la tierra.

Así, De Sousa Santos estimula la movilización popular, la iniciativa local, el acto comunitario de producción de saberes según las situaciones concretas de las poblaciones que reclaman y buscan unos medios para proporcionarse un mejor estar en su propio hábitat. Hábitat que es susceptible de compenetrarse con el ser humano en la medida en que ya 
no es preciso controlar, sino contemplar para aprender a vivir, con lo cual el saber práctico se constituye en un sentido común que no cause traumas psíquicos, naturales o cósmicos.

Morin, sin embargo, no se muestra partidario de reivindicar la posición de tal o cual grupo humano localizado aquí o acullá. Él desea que las bondades de la ciencia y las humanidades se derramen por igual sobre todos los hombres de la Tierra. No hace Morin distinción alguna. Parece ser más ecuménico que De Sousa Santos. En este punto, Morin (2009) adopta un tono entre científico y filosófico:

Yo hablo de auto-eco-organización, de la relación entre autonomía y dependencia. Desde la visión clásica del determinismo no podemos entender la autonomía; únicamente en la metafísica cabía la autonomía de la mente, del espíritu, pero la metafísica no tenía raíces en el mundo real. Tenemos necesidad de depender del ambiente, para la nutrición y también para el conocimiento, para encontrar esta nutrición, para defendernos de todos los enemigos, pero esta dependencia es la que permite la autonomía. Esto significa que la autonomía se construye sobre la dependencia cada vez más amplia (p. 33).

En cambio, la epistemología del Sur que propone De Sousa Santos (2009) asume una posición comprometida y militante, así:

No solo recuperar conocimientos suprimidos o marginalizados, sino también identificar las condiciones que tornen posible construir nuevos conocimientos de resistencia y de producción de alternativas al capitalismo y al colonialismo globales. En esto consiste la propuesta de una ecología de los saberes. (p. 12)

Sobre este particular, Morin no solo evita el discurso político, la vindicta y el empleo de la ciencia para cobrarse alguna factura. Para él, la sociedad, el individuo y la especie son una trinidad que se organiza y desorganiza al modo de la termodinámica o de un circuito cibernético. Dice Morin (2008):

Debemos trazar la noción de humano no de un modo separado del individuo, la sociedad, la especie; sino los tres como una trinidad inseparable, una relación recursiva, una relación co-circular, con una relación a la vez complementaria y antagonista, con una relación individuo-Estado y también individuoreproducción, nosotros hacemos el amor sin hacer reproducción. Relación antagonista y complementaria de los tres, y también un tercer concepto complejo: hologramático, es decir, que nosotros podemos saber que el todo de una especie se encuentra en cada célula de un individuo (p. 35).

Lo que para De Sousa Santos es una ecología de saberes como forma de adquirir soberanía y afirmar la identidad cultural, es para Morin (2008) un conocimiento ecológico basado en "la contextualización de la historia humana y del planeta Tierra" (p. 37).

Según lo anterior, podemos establecer que existen dos lenguajes, dos aproximaciones, dos ideologías y dos intenciones que, a pesar de 
complementarse, suscitan un contraste que va más allá de una forma de enunciar la realidad. Pues resulta evidente que para De Sousa Santos a la historia hay que ayudarla, hay que fijarle un rumbo, hay que hacerla. Y esa ayuda, ese rumbo y ese hacer son producto de la voluntad humana. Mientras que para Morin el individuo es una partícula de una máquina no trivial que es la sociedad, y al mismo tiempo es un elemento de la especie con sus dependencias y emergencias. Le reconoce Morin libertad al hombre, pero también lo encuentra sometido a la sociedad y a los dictados de la especie.

En virtud de lo anterior, y para ampliar el concepto epistémico propuesto por De Sousa Santos, que busca una justicia cognitiva que se traduzca en justicia social para enfrentar las experiencias, hábitos y conocimientos hegemónicos, me permito citar:

La ecología de saberes es una epistemología desestabilizadora hasta el punto que se compromete en una crítica radical de las políticas de lo posible sin el rendimiento a una política imposible. Para la ecología de saberes no es central la distinción entre estructura y agencia, como es el caso de las ciencias sociales, sino la distinción entre acción conformista y lo que yo he propuesto llamar acción-con-clinamen. Acción conformista es la práctica rutinaria, reproductiva y repetitiva que reduce el realismo a lo que existe y precisamente porque existe. Para mi noción de acción-con-clinamen [...] es [...] la capacidad de desviación atribuida por Epicuro a los átomos de Demócrito. [...] La ecología de saberes está constituida por sujetos desestabilizadores, individuales o colectivos, y es, al mismo tiempo, constitutiva de ellos. [...] La construcción social de tal subjetividad debe suponer experimentar con formas excéntricas o marginales de sociabilidad o subjetividad dentro y fuera de la modernidad occidental, esas formas que han rechazado ser definidas según criterios abismales. (De Sousa Santos, 2009, pp. 193-194).

De tal manera que, para este sociólogo portugués, los saberes laterales, arrinconados por el conocimiento colonial y excluidos de los centros de poder deben hacerse visibles para intervenir la realidad, y no para crear una representación de la realidad. Por eso, desde su perspectiva, no es concebible una neutralidad ética con relación a la ciencia. Y mientras que Morin opta por la integración sistemática de las ciencias, por promover la diseminación ecuménica del conocimiento y por llevar la conciencia a la ciencia, De Sousa Santos se la juega por la reivindicación de los saberes originarios de América Latina y por una epistemología de la resistencia.

Vale añadir que uno de los saberes propios de América Latina, amén de los ancestrales, lo constituye aquella literatura, que bajo las denominaciones de lo real maravilloso, realismo mágico y lo fantástico rioplatense, ha prodigado toda clase de revelaciones que, lejos de ser una artimaña literaria al estilo de los autores surrealistas, ha devenido en una peculiar forma de comprender una realidad, una atmósfera y una historia que sobrepasan a la razón, la lógica tradicional, el cartesianismo y la linealidad imperantes en Occidente.

Si escribir es soñar con los ojos abiertos y creer a pie juntillas en la fábula que se cuenta, pues la verdad que desde el Diario de Colón se ha 
relatado acerca de estas tierras y sus habitantes y acontecimientos, no es nada distinto a la pura realidad que nos rodea. No es pues imposible que ciencias y letras se encuentren en algún punto para amplificar, diversificar, multiplicar e interconectar la realidad exterior y privada del individuo. Por ahora estamos bordeando el misterio.

\section{Conclusiones}

Si bien es cierto que los estudios contemporáneos están divididos en ciencias de la complejidad y pensamiento complejo, la intervención de un factor de carácter humanístico y estético como la literatura puede contribuir a entender que la conciliación entre esas dos miradas es posible a partir de la integración holística que permite la escritura artística.

El recurso literario de la metáfora o la imagen, de modo similar a las construcciones no menos alegóricas como las matemáticas en las ciencias, puede ser un medio, más que complementario, decisivo, para conocer la realidad plural del hombre y del mundo. También para religar los aspectos de esa realidad poliédrica. Aunque es significativa la particularidad de la narrativa para bucear por los pasillos interiores del ser humano, la imaginación y la belleza no dejan de recibir notables influencias sociales, históricas, políticas y, naturalmente, tecnológicas y científicas para componer una visión más o menos total de la especie humana y del mundo. Total, en la medida en que es posible integrar factores objetivos y subjetivos en el proceso del conocimiento. Pues por muy ficticia que sea una obra, no por ello está divorciada de su contexto, del pasado, de las inquietudes colectivas, de las aprehensiones de la época, de los acontecimientos del presente, de las elucubraciones acerca del futuro. Razón y emoción están presentes, y no son solamente las del autor; también están presentes la razón y la emoción de sus semejantes.

No sobra recordar aquí que el poeta londinense William Blake la emprendió en contra de tres intocables de la orilla contraria a la suya, a saber, Bacon, Locke y Newton, portavoces del deísmo, el racionalismo y el cientificismo. A ellos, y a los de su línea, Blake les dedicó en su "Visión memorable", del libro Matrimonio del Cielo y el Infierno, publicado en 1783, las siguientes líneas:

Si las puertas de la percepción estuvieran purificadas, todas las cosas se le habrían mostrado al hombre como son, infinitas.

Pero el hombre se encerró en sí mismo, hasta el punto de ver todas las cosas a través de las estrechas grietas de su caverna. (Blake, 1783/1983, p. 53)

En ese sentido, podríamos sostener que un vehículo para pretender purificar las puertas de la percepción es precisamente la literatura, puesto que los creadores, sin mayores traumatismos, aceptan la pluralidad, la distinción y el misterio del mundo. Igualmente, el autor narrativo, como 
el científico, quiere comunicar lo indecible, lo que ocurre es que se vale de una materia prima escurridiza, las palabras, que no está concebida para interpretar aquello más íntimo y profundo del corazón y de la mente del ser humano. A ello se debe que la literatura sea generadora de símbolos y de diversidad de significados. Mientras que la ciencia dice una cosa y solo esa, sin posibilidad de ambigüedades. Además, la ciencia simplifica y unifica, al tiempo que las letras diversifican y especulan. ¿Es ello anticientífico? No necesariamente. Lo que hace la literatura es brindar una explicación ampliada de las manifestaciones intrínsecas y conectar estas con el mundo de afuera.

A pesar de las diferencias de todo orden, la complejidad de la literatura ha contribuido a un conocimiento más amplio del ser humano y de sus relaciones con la realidad. A propósito, la novela El extraño caso del $D r$. Jekyll y Mr. Hyde de Robert Louis Stevenson sirvió de base para que Freud postulara los tres conceptos básicos de la teoría psicoanalítica: el ello, el yo y el superyó. De manera que en el ello está el contenido inconsciente, y expresa las pulsiones y los deseos. El superyó es la instancia moral, gobernada por normas y prohibiciones. Y el yo es el mediador entre los deseos inconscientes y las reglas culturales. Quiere el placer, pero dentro de ciertos límites sociales. Stevenson, por lo tanto, creó a un científico que fabricaba una poción capaz de separar la parte más humana del individuo de la más bestial. El caso resultó ser la descripción clínica de lo que más tarde se llamaría trastorno disociativo de identidad.

Este es apenas un ejemplo de lo que en ocasiones ha supuesto la literatura para la ciencia. No por expresarse mediante lenguajes distintos significa que estas formas de conocimiento tengan que vivir divorciadas.

\section{Referencias}

Blake, W. (1983). El matrimonio del Cielo y el Infierno (S. Capurro, Trad.). Visor. (Original en inglés publicado en 1783)

De Sousa Santos, B. (2009a). Una epistemología del Sur: La reinvención del conocimiento y la emancipación social (J. G. Gandarilla Salgado, Ed.). Siglo XXI.

Francisco (2015). Laudato si. Paulinas.

Gell-Mann, M. (1998). Luz temprana. En M. Gell-Mann. En El quark y el jaguar (pp. 29-58). Tusquets.

Gramsci, A. (2014). Crónicas de Turín. Gorla.

Heidegger, M. (1958). ¿Qué significa pensar? Nova.

Huxley, A. (1966). Literatura y ciencia. Edhasa. 
Maldonado, C. E. (2007). El problema de una teoría general de la complejidad. En E. Maldonado (Ed.), Complejidad: ciencia, pensamiento y aplicaciones (pp. 101-132). Universidad Externado de Colombia.

Maldonado, C. E. (2009). Exploración de una teoría general de la complejidad. En E. Maldonado, Complejidad: revolución cientifica y teoria (pp. 113-143). Universidad del Rosario

Maldonado, C. E. (2009). La complejidad es un problema, no una cosmovisión. UCM Revista de Investigación, 13, 42-54.

Morin, E. (1981). El espíritu del valle. En E Morin, El Método 1: La naturaleza de la naturaleza (pp. 21-39). Cátedra.

Morin, E. (1999). El paradigma de la complejidad. En E. Morin, Introducción al pensamiento complejo. (pp. 87-131) Gedisa.

\section{SE TRATA DE UNA CONFERENCIA DE MORIN, RECOGIDA EN UN DOCUMENTO TITULADO "PENSANDO LA COMPLEJIDAD":}

Morin, E. (2008). Complejidad restringida y Complejidad generalizada o las complejidades de la Complejidad. En P. Sotolongo (Presidencia), Pensando la Complejidad. III Seminario Bienal Internacional-Complejidad, llevado a cabo en la Universidad de Camagüey, Cuba. Instituto de Filosofía. Consejo de Ciencias Sociales. Academia de Ciencia. Cuba. Pensando la complejidad (No.V. Año II. . 5, pp. 27-41).

Morin, E. (2011). La Via: para el futuro de la humanidad. Paidós.

Ospina, W. (2018). El taller, el templo y el hogar. Penguin Ramdom House.

Prigogine, I. y Stengers, I. (2004). La nueva alianza: metamorfosis de la ciencia (M. C. Martín Sans, Trad.). Alianza.

Prigogine, I. (1983). La lectura de lo complejo. En I. Prigogine. ¿Tan solo una ilusión? (pp. 45-63). Tusquets.

Prigogine, I. (1993). La termodinámica de la vida. En I Prigogine. ¿Tan solo una ilusión? (pp. 305-332). Tusquets.

Rodríguez Zoya, L. G. y Aguirre, J. L. (2011). Teorías de la complejidad y ciencias sociales. Nómadas, 30(2), 147-166. https://doi.org/10.5209/rev_ NOMA.2011.v30.n2.36562

Sábato, E. (1981). Uno y el universo. Seix Barral.

Tagore, R. (1976). El sentido de la vida. Aguilar.

Yáñez, A., Casigoli, R., Lapoujade, M., Wunenburger,JJ. (2009). Gastón Bachelard y la vida de las imágenes. UNAM. 